\title{
sciendo
}

DOI 10.2478/sbe-2019-0025

SBE no. 14(2) 2019

\section{THE CAC 40 INDEX'S REACTION TO TERRORIST ATTACKS: THE CASE OF CHARLIE HEBDO}

KHOURY RIM EL

Notre Dame University Louaize, Lebanon

\begin{abstract}
:
Over the last decades, terrorism has become a global phenomenon to which every society is exposed from time to time. Terrorist attacks can have many economic consequences that may affect a number of sectors, including the capital market. The main goal of this paper is to examine the reaction of the CAC40 index to one terrorist attack, mainly "Charlie Hebdo" using an event study methodology. By calculating the abnormal returns and the cumulative abnormal returns in the event period, the results obtained show no significant abnormal returns on the day of the terrorist attack suggesting that the market had directly absorbed the effect of the attack. Thus, the findings suggest that the French market is semi-strong efficient. Investors can rely neither on past information nor on publicly available information to make abnormal profits.
\end{abstract}

Key words: Efficient Market Hypothesis, CAC40, terrorist attack, January effect, Mean Market Adjusted

\section{Introduction}

Fama (1970) introduced the famous efficient market hypothesis (EMH) a few decades ago according to which stocks prices fully reflect all available information. This implied that, in an efficient market, security prices fluctuations are considered to be completely random. Over the years, researchers had tried to find evidence against the efficient market hypothesis and anomalies related to the EMH started to appear in both developed and emerging markets.

At the same time, terrorist attacks have become an international event during the recent history as they have changed the dynamics of worldwide capital markets (Cam, 2007). Terrorism has become the first security threat in the world and the main danger to the financial system. According to the CNBC news, developed countries across Europe are becoming more and more vulnerable to terrorism due to the rising power of Islamic State (ISIS) and other Islamist extremist groups (Barnato, 2015). The terrorist attack of September 11, 2001 on the twin towers in New York is an event that changed the face of American country and provided typical evidence of the potential economic damage caused 
by terrorism. Enders and Sandler (2006) stated in their paper that the estimated cost of the attack was $\$ 48.7$ billion causing the death of 3,000 individuals. Beyond losses of human capital and infrastructure, stock markets also responded to the event and the volatility in the financial markets had increased. The US equity market indices fell dramatically and caused a crisis not only in the US but also through the rest of the world (Bruck \& Wickstrom, 2004). On January 14th, 2015 the BBC news stated that France has been emerging from one of its worst security crises in decades after three consecutive days of terrorist attacks which brought bloodshed to the capital Paris and its surrounding areas. It began with a massacre at the offices of "Charlie Hebdo" magazine on Wednesday 7th of January and ended with a huge police operation to stop the suspects after two days whereby two policewomen were killed. With the predominance of terrorism as one of the main international security threat, the number of papers that tried to test the impact of the terrorism on the capital market in terms of return and volatility has grown over time (Barros \& Gil-Alana, 2009; Chesney, Reshetar, \& Karaman, 2011). Some have found that terrorism has a negative impact on asset valuation, investment decisions, portfolio allocation; in addition to increasing volatility by affecting the market risk premium (Drakos, 2010; Chen \& Siems, 2004; Kollias, Papadamou \& Arvanitis, 2013).

Given the rise in the terrorist attack, this paper will test the reaction of the French market, taking into consideration the CAC40 index, to the "Charlie Hebdo" terrorist attack using an event study methodology. The rest of this paper is organized as follows. The following section will describe the literature review and present the empirical findings. Section 3 will state the research question and the hypotheses to be tested in this paper. Afterwards, data, variables, and research model will be defined in Section four. Section five will present and analyze the empirical findings obtained, while Section six will conclude.

\section{Literature Review}

\section{Theories and Forms of Efficient Market Hypothesis}

Although the concept of efficient market hypothesis (EMH) was firstly introduced by the French mathematician Louis Bachelier (1900), it was firstly explained by Fama (1970). Under the "Efficient Market Hypothesis", investors cannot use past prices to predict future ones; information is randomly provided; and no one can speculate by buying or selling under and overvalued stocks (Fama, 1970). The EMH explained by Fama has been used as a cornerstone for all future market efficiency studies.

Malkiel (2003) associated the definition of the EMH with the Random Walk theory, stating that all subsequent price changes are characterized by a random departure from earlier prices and the flow of information is directly reflected in the stock price.

The expected returns can be stated in the following mathematical equation (Fama, 1970):

$\mathbf{E}\left(\widetilde{\mathbf{P}}_{\mathrm{j}, \mathrm{t}+1} \mid \emptyset_{\mathrm{t}}\right)=\left[\mathbf{1}+\mathbf{E}\left(\tilde{\mathbf{r}}_{\mathrm{j}, \mathrm{t}+1} \mid \emptyset_{\mathrm{t}}\right] \mathbf{p}_{\mathrm{jt}}\right.$

Where:

$E$ is the expected return or value

$P_{\mathrm{jt}}$ is the price of security $\mathrm{j}$ at time $\mathrm{t}$. 
$P_{j, t+1}$ is the price of security $j$ at time $t+1$; with reinvestment of any intermediate cash income from the security

$R_{j, t+1}$ is the one period percentage return

$\emptyset_{\mathrm{t}}$ is a general symbol for whatever set of information is assumed to be "fully reflected" in the price at $\mathrm{t}$.

$$
\begin{aligned}
& Z_{j, t+1}=r_{j, t+1}-E\left(r_{j, t+1} / \emptyset_{t}\right) \\
& E\left(Z_{j, t+1} / \emptyset_{t}\right)=0
\end{aligned}
$$

Where $Z_{j, t+1}$ is the unexpected or excess return of security $j$ at time $t+1$ defined as the difference between the observed return, $r_{j, t+1}$, and the expected return based on the information set $\emptyset_{\text {t. }}$.

The EMH is divided into three forms on the basis of information: Weak form efficiency, Semi-strong form efficiency, and Strong form efficiency. Weak form efficiency emphasizes on the point that prices of stocks already reflect all historical information. Thus, past prices do not provide foresight about future prices so that excessive profits cannot be made by considering the past prices of shares, indicating the invalidity of technical or chartists analysts. Because information occurs randomly and because price movements are the result of that information, price changes are random too (Fama, 1970). Semi-strong form efficiency asserts that stock prices reflect all publicly available information and not only past information. In this market, investors cannot make abnormal profits by relying on public information nor by investing directly after news releases. According to this form, any public announcements such as earnings, stock splits, takeovers, etc are reflected in the stock prices. From that perspective, not only technical analysis is not valid in earning abnormal returns, but also fundamental analysis. Strong form efficiency is the most comprehensive form of EMH and points out that all prices must, in addition to the past prices information and public information, reflect all private information so that no one can have an advantage while trading. This represents the strongest form of market efficiency and even insiders cannot make abnormal profit based on their knowledge (Hameed, Ashraf, \& Siddiqui, 2006). The main assumption is that the stock price fully reflects all information even the one which has not been released to the public yet.

\section{Market Anomalies}

The Efficient Market Hypothesis suggests that markets are rational and prices always fully reflect available information so that no investor can beat the market and realize abnormal profits. Nevertheless, it is found in different stock exchanges in the world that these markets are deviating from the rules of the $\mathrm{EMH}$. Those deviations which cannot be explained through the Efficient Market Hypothesis are called financial market anomalies. They indicate the presence of an arbitrage opportunity because of market inefficiency or scantiness in the underlying asset pricing model.

As defined by Archana, Safeer, \& Kevin (2014), "financial market anomalies are cross sectional and time series patterns in security return that are not predicted by a central paradigm or theory" (Archana, Safeer, \& Kevin, 2014, p.128). Financial market anomalies can be divided into three basic types: Calendar or seasonal anomalies, Fundamental anomalies, and Technical anomalies. 
After they were acknowledged and investigated in hundreds of papers, anomalies seem to fade away in the current literature. As shown by Schwert (2003), many of the important findings in the finance literature regarding market anomalies do not hold up anymore.

\section{Empirical Evidence on the Semi-Strong Efficient Market Hypothesis}

Most of the empirical studies related to the Efficient Market Hypothesis had investigated whether prices 'fully reflect' particular sets of information. The early researchers were focusing on the weak form of the EMH where historical prices are considered to be the information sets. Afterwards, attention had been turned to the semistrong form which tests the speed of a price adjustment to new publicly available information such as annual reports, dividends and earnings announcements, stock splits.... Event study method has been the most widely used method when it comes to semi-strong market efficiency tests. It gives a clear picture for the speed of adjustment of prices to information for many types of firm specific events (Fama, 1991). Fama, Fisher, Jenwsen, \& Roll (known as the FFJR) (1969) were the first researchers to adopt the event study methodology in their study, which had been broadly used in different studies in order to examine the security price behavior around events earnings announcements, stock splits, accounting rule changes, etc (Binder, 1998). The aim is to examine the security price behavior over a period, from a specified number of days before the occurrence of the event to another specified period after the event. According to Dimson and Mussavian (1998), "the market appears to anticipate the information, and most of the price adjustment is complete before the event is revealed to the market" (Dimson \& Mussavian, 1998, p.95)

Market reaction to accounting information. Starting with the market reaction to accounting information, Benos and Rockinger (2000) investigated the French market response, mainly the SBF 120 index, to earnings announcements from 1995 to 1997. Using a Mann-Whitney single sided nonparametric test, they found that prices adjust very quickly to public information. Lardic and Mignon (2003) studied the impact of public information using daily data collected for two major indices in France, CAC40 and MIDCAC for the period of five years from January 1995 until December 1999. By applying two nonparametric tests (the threshold test and the run test), they found that earnings announcements have great impact on stock prices, thus questioning the validity of the EMH in its semi strong form. Mallikarjunappa and Dsouza (2013) studied the semi strong market efficiency in the Indian market taking into consideration the earnings announcements of companies in the BSE200 index. Using the event study methodology, they concluded that the Indian stock market is not efficient in the semi strong form because the Indian market is slow in reacting when it comes to publicly available information. Thus, investors can make abnormal profits by selling stocks after the results of the earnings are being announced.

Stock split. Garcia De Andoain and Bacon (2009) studied the impact of 36,714 stock split announcements in the S\&P 500 index on stock prices, using the event study methodology. The results confirm that stock split announcements did not affect the stock price on the same day, showing that stock price exhibits a positive reaction up to 27 days prior to the announcement, supporting the semi strong market efficiency. Hua and Ramesh (2013) studied the impact of stock split announcement on the stock price in Colombo Stock 
Exchange (CSE) using 64 events from 52 companies and a standard event study methodology for the period 2009 to 2012. Their results show that the market positively reacts for stock splits, but this reaction occurs before the announcement of the split. Thus, the results of this study supported the efficient market hypothesis in its semi-strong form.

Block Trading. In 2010, Agarwalla and Pandey analyzed the speed of market response to information associated with block trades in the Indian capital market. The covered sample was approximately all the stocks listed in the Indian market, for almost nine years or actually 2,164 trading days from January 1999 until August 2007. By using the 'transaction time event approach' methodology, their results ensured the availability for the semi strong market efficiency showing that prices start increasing eight minutes before block purchases, and in case of block sales, prices quickly revert leaving very small permanent price impact (Agarwalla \& Pandey, 2010). Alzahrani, Gregoriou, and Hudson (2012) studied the price impact of block trades for all listed firms in the Saudi Stock Market (SSM). They collected a high frequency data sampled at a one minute interval for almost four consecutive years from January 2005 until October 2009 with 16,076,414 records. They defined a block trade as any trade with over 10,000 shares giving a total of $4,221,870$ trades. They found that investors can make abnormal profits through benefiting from overreaction before block trading and price reversals after block trading, thus cancelling the presence of the Efficient Market Hypothesis in its semi strong form in the Saudi Stock Market.

\section{Market efficiency during terrorist attacks}

Most of the studies were conducted about September 11, 2001 attack on the twin towers in New York, though few have broadened the perspective and studied the efficiency of other markets during terrorist attacks (Karolyi \& Martell, 2006). Terrorist attacks might have serious implications on the prices of stocks and bonds.

Chen and Siems (2004), by studying the magnitude of September 11 attack on the financial market, reported a significant impact, but a fast recovery for US markets as compared to other markets. Karolyi and Martell (2006) did a very broad research on the reaction of capital markets to terrorist attacks taking into consideration 75 such events for publicly traded companies in eleven different emerging and developed markets. They found that, on ave0rage, there has been a price decline of $-0.83 \%$ around the day of the attack. Nikkinen Omran, Sahlstrom, and Aijo (2008) had also examined the effect of September 11 on 53 markets and found an increased volatility. As for the short run negative effects, it varied across regions depending on the degree of their integration. In 2012, Colman tested the US market efficiency by examining nine bombings that have been attributed to Al Qaida since 1998, in addition to identifying whether investors were trading stocks with advanced knowledge of the attacks. Going beyond the event study methodology, Colman (2012) examined minute by minute the prices during the attacks. He concluded stating that most of these terrorist attacks had minimal impacts on financial markets, adding that on average, markets took less than 90 minutes from the time of the attack to fully price the effects, which strongly favours the Efficient Market Hypothesis. Subsequently, he added that there was no indication of insider trading around terrorist attacks, given that the attacks were not timed to generate abnormal returns. Rehman, 
Luqman, and Suleman (2011) tested the semi strong market efficiency in the Pakistani stock market by taking into consideration five terrorist attacks and two natural disasters between 2005 and 2010. Using the standard event study methodology and data for the KSE-100 index, they concluded that the market is efficient in the context of terrorism; however when it comes to natural disasters, the market behaved inefficiently and investors had the opportunity to make abnormal profits. Suleman (2012) studied the market efficiency around terrorist attacks in Pakistan. Employing the EGARCH model, he found that terrorist attacks have a negative impact on the Karachi Stock Exchange (KSE 100), thus increasing the volatility of this index. Furthermore he concluded that the oil and gas markets are not statistically significant in their response to terrorist attacks in Pakistan, indicating that this type of event did not have any impact on the volatility of these two sectors.

\section{Research Question and Hypothesis}

The semi-strong form efficiency asserts that stock prices reflect all publicly available information and not only past information. Terrorist attacks are considered as public information, and their consequences should be directly reflected in stock prices. Hence, showing that the terrorist attack "Charlie Hebdo" was not directly absorbed by the French market disobeys the assumption of semi-strong market efficiency and gives investors the ability to generate abnormal profits.

Thus, the main objective of this paper is to test the semi-strong form efficiency of the French market, by examining whether CAC 40 stock index was efficient enough to absorb the consequences of the terrorist attack "Charlie Hebdo", or whether the terrorist attack had caused an abnormal return in the French market. Therefore, the hypothesis tested is:

The Null Hypothesis ( $\mathrm{H} 0)$ : The CAC 40 stock index is semi-strong efficient

The Alternative Hypothesis ( $\mathrm{Ha})$ : The CAC 40 stock index is semi-strong inefficient

\section{Research Model}

\section{Data and Its Source}

The CAC 40 (CAC stands for Compagnie Nationale des Agents de Change) is a French stock market index that measures the performance of the 40 largest, publicly traded companies on the Euronext market. It is a capitalization-weighted index that is considered as one of the main indices in the Euronext alongside with Brussels BEL 20, Amsterdam AEX and Lisbon PSI 20. Actually, the CAC 40 is considered to be a strong indicator of the economic performance of not only France, but of Europe as a whole (Ryland, 2009).

In this study, secondary data for the CAC 40 stock index will be used to test the semi-strong efficiency of the French market. Historical daily prices from July 31, 2014 until January 19, 2015 are collected from Yahoo Finance resulting in 162 observations. 


\section{Variables}

The key variables used are the single day index return on CAC 40 as well as the abnormal returns that are derived from the index returns. The return is calculated as

$$
\mathbf{R}_{\mathbf{t}}=\ln (\mathbf{P t} / \mathbf{P t}-\mathbf{1})
$$

The event studied in this paper is the terrorist attack on the French magazine "Charlie Hebdo" which occurred on the 7th of January 2015. Thus, the data was collected 150 days before the attack until 10 days before the event. The event window begins 10 days before January 7, 2015 and ends 10 days after. Additionally the time for the index to rebound from the event was examined to estimate the impact of the attack in terms of market recovery.

\section{Research Methodology}

To test the impact of the terrorist attack on the CAC 40 index, an event study methodology will be used as it can be considered as the best way to test the efficiency of the French market.

Event studies go back to Dolley in 1933, who studied the price effects of stock splits on a sample of 95 stock splits from 1921 until 1931. In the late 1960s, Ball and Brown (1968) and Fama et al (1969) introduced the event study methodology, which was modified in 1985 by Brown and Warner.

"The cleanest evidence on market efficiency comes from event studies, especially event studies on daily returns. When an information event can be dated precisely and the event has a large effect on prices... as a result, event studies can give a clear picture of the speed of adjustment of prices to information" (Fama, 1991, p.1607)

The methodology can be divided into seven steps as shown in Figure 1 (Campbell, Lo, \& MacKinlay, 1997)

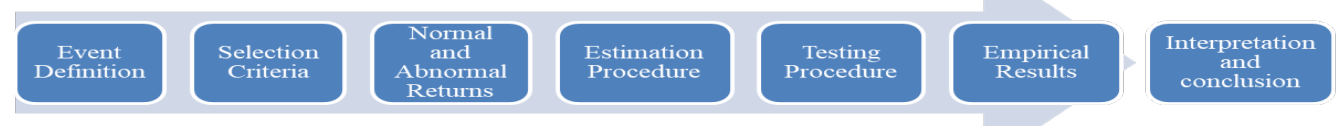

Figure 1. The event study methodology in seven steps.

Steps one and two: Event Definition and Selection Criteria. The first step is to identify the event of interest and the event window. In this paper, the event consists of the "Charlie Hebdo" terrorist attack and the event window is the time period during which the event actually happened. In fact, the event window should involve more than one day in order to capture any potential effects before or after the event (Campbell et al, 1997). Then, it is important to determine the selection criteria for the chosen data. Data can consist of daily, weekly or monthly prices depending on the model in use (Campbell et al, 1997). In this paper, daily data for the CAC40 index exported from YahooFinance will be used in order to calculate normal and abnormal returns.

Step three: Normal and Abnormal Returns. As defined by Bowman (2006), the abnormal return is the actual return of the security over the event window (ex-post) minus 
the return that would be expected if the event did not take place. Campbell et al (1997) defined the abnormal return as in the following formula:

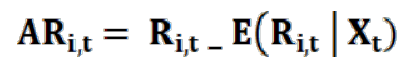

Where $A R_{i, t}$ is the abnormal return, $R_{i, t}$ is the actual return and $E R_{i, t}$ is the normal return. $X_{t}$ is the conditioning information for the normal performance model.

The normal returns can be estimated in two ways, statistical and economic models. Statistical models include mean adjusted model, market adjusted model and the market model, while economic models consist of the Capital Asset Pricing Model (CAPM) and the Arbitrage Pricing Theory (APT) (Brown \& Warner, 1985).

First, according to the Mean Adjusted Model, the ex-ante expected return of a given security $i$ is the mean of the historical returns calculated over an estimation window ( $T_{0}-T_{1}$, Figure 2) (Brown \& Warner, 1980). Thus, the mean adjusted model can be mathematically written as:

$$
\boldsymbol{A} \boldsymbol{R}_{i t}=\boldsymbol{R}_{i t_{-}} \bar{R}_{j}
$$

Where $A R_{i t}$ is the abnormal return for stock index $i$ at time $t, R_{i t}$ is the actual return of stock index $i$ at time period $t$ and $R_{j}$ is the mean of the stock index's daily return in the estimation period, which will be defined in Step 4.

Second, the Market Adjusted Model assumes that the expected return of a security is equal to the market return obtained in the estimation period. Thus, the abnormal return of a security can be written as the difference between the actual return of the security and the market portfolio as in the following formula:

$$
\boldsymbol{A} \boldsymbol{R}_{\text {it }}=\boldsymbol{R}_{\text {it }}-\boldsymbol{R}_{\text {market }}
$$

Third, according the Market Model, the return of a security is related to the return of the market portfolio, and it can be written as:

$$
\mathbf{R}_{\mathrm{it}}=\boldsymbol{\alpha}_{\mathrm{i}}+\boldsymbol{\beta}_{\mathrm{t}} \mathbf{R}_{\mathrm{mt}}+\boldsymbol{\epsilon}_{\mathrm{it}}
$$

Where $R_{m t}$ is the market portfolio. $\epsilon_{i t}$ is the zero mean disturbance term. $\alpha_{i}$ and $\beta_{t}$ are the parameters of the market model.

The second category of estimating abnormal returns consists of the economic models, mainly Capital Asset Pricing Model (CAPM) and the Arbitrage Pricing Theory (APT). The CAPM is an equilibrium theory where the expected return of an asset is described as a linear function of its covariance with the return of the market portfolio. The APT, as explained in Ross (1976), is an asset pricing theory where in the absence of asymptotic arbitrage, the expected return of a security is determined by its covariance with multiple factors.

Campbell et al (1997) mentioned that the use of economic models complicates the steps of the methodology, with no important practical advantage over the statistical models. They also added that "there seems to be no good reason to use an economic model rather than a statistical model in an event study" (Campbell et al, 1997, p. 157).

Given that the relationship between all these models can be observed and the choice of the model should have only a little influence on the results, this study will use the mean adjusted model in order to calculate the abnormal returns in the event period from 28th of December 2014 until 17th of January 2015, using the following formula:

$$
A R_{C A C 40, t}=R_{C A C 40, t_{-}} \bar{R}_{C A C 40}
$$


Where ARCAC40,t is the abnormal return of the index CAC40 on day $t$ (should be calculated on a daily basis for the entire event period), RcAC40,t the actual return of the CAC40 index on each day in the event window, and $\bar{R}_{\text {CAC40 }}$ is the mean of the daily returns of the CAC40 index over the estimation period.

Step four: Estimation Procedure. Estimation window, event window and post event window need to be defined. The estimation window is a time period prior to the event defined as the interval between $T_{0}$ and $T_{1}$, the event date is $t=0$, the event window is the period that lies around the actual event defined as between $T_{1}$ and $T_{2}$, while the post-event window follows the event window between $T_{2}$ and $T_{3}$ (visualized in Figure 2).

The estimation period of 150 days was taken following Corrado and Zivney (1992) who suggested using more than 100 days to estimate the return for the studied index to obtain accurate results for the methodology. The event day $(t=0)$ is examined to find evidence of the reaction of the index to the terrorist attack. The choice of the event window depends on what is being studied (Armitage, 1995). The most popular event windows used for event studies are $(-1 ;+1),(-5 ;+5)$ and $(-10 ;+10)$. The shorter the event window, the easier to detect abnormal returns and the easier to control for all confounding effects by minimizing the risk of non-event spillovers (Armitage, 1995). In this study, $(-10 ;+10)$ will be used.

The returns for the mean adjusted model will be calculated over 150 days (estimation window), as suggested by Peterson in 1989, from $t=-160$ until $t=-10$ using the following formula:

$$
\overline{\mathbf{R}}_{\mathrm{CAC40}}=\frac{1}{150} \sum_{-10}^{-160} \mathbf{R}_{\mathrm{CAC40,(-160,-10)}}
$$

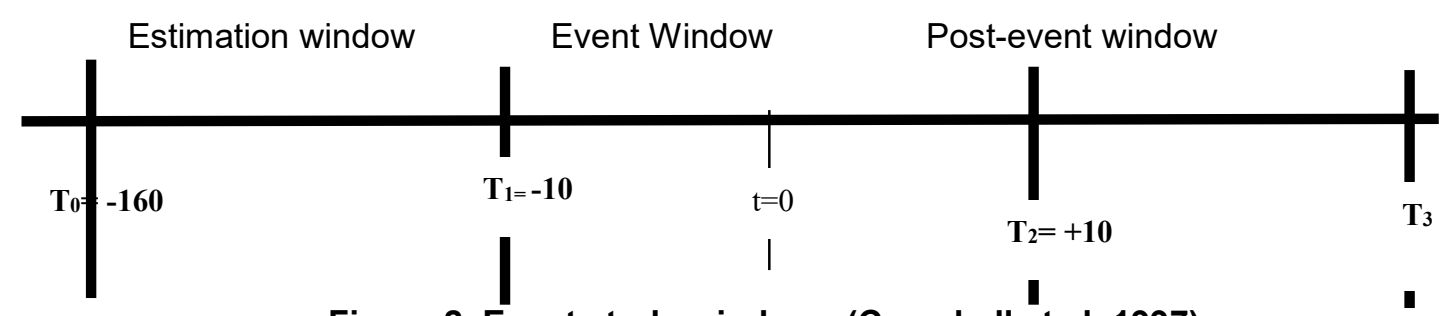

Figure 2. Event study windows (Campbell et al, 1997)

Step five: Testing procedure. The next step requires designing the testing framework for the calculated abnormal returns. A null hypothesis should be created to test the effect on the event on the price of the security.

$\mathrm{HO}$ : The abnormal return shows no statistical significant impact on the security's return $(A R=0)$

Ha: The abnormal return shows statistical significant impact on the security's return $(A R \neq 0)$

Testing the significance of the abnormal returns can be done using parametric and non-parametric tests. Parametric tests, such as T-test, assume certain assumptions to be satisfied such as a normal distribution for individual firms while non parametric tests such as the sign test and the Wilcoxon signed rank test do not. Brown and Warner (1980) asserted that the usage of non-parametric tests has no advantages over the usage of 
parametric tests when testing abnormal returns and stated that: "under the null hypothesis, the tests do not reject at the correct level" (Brown \& Warner, 1980, p. 218). In addition, Campbell et al (1997) argued that parametric tests usually have a better statistical power than non-parametric tests. Thus, this paper will use a student test (Equation 10) in order to test whether the mean of the abnormal returns is different from zero. . The t-test can be explained as in the following formula:

$$
\text { t-statistic }=\frac{\bar{x}-\mu_{0}}{s / \sqrt{n}}
$$

When the abnormal returns are calculated, the Cumulative Abnormal Returns (CAR), which is the sum of all abnormal returns on each day of the event window, should be calculated too. Mathematically it can be written as:

$$
\operatorname{CAR}_{\mathbf{i}}\left(\mathbf{t}_{1}, \mathbf{t}_{2}\right)=\sum_{\mathbf{t}=\mathrm{t}_{\mathbf{1}}}^{\mathbf{t}_{2}} \operatorname{AR}_{\mathrm{it}}
$$

Step six and Step seven: Empirical Results, Interpretation, and Conclusion. After conducting the significance tests on abnormal returns, empirical results should be drawn to verify the presence of any statistical significant abnormal return on each day of the event window. Finally, results should be analyzed and interpreted. Ideally, empirical results will lead to insights about the mechanisms by which the event had affected security prices.

\section{Findings and Analysis}

If the markets are semi-strong efficient, then a new information such as a terrorist attach will be immediately incorporated into the security prices. A terrorist attack is seen as unanticipated event, a sudden shock which is suit well to the hypothesis of efficient capital markets.

\section{Steps 1-4}

The event examined in the paper is the terrorist attack on the French magazine "Charlie Hebdo" on the 7th of January 2015. 150 trading days are considered as the estimation period and 21 trading days as the event window, whereby 10 days are taken before and after $\mathrm{t}=0$, which is the date when the event actually happened. Daily prices for the CAC40 index are used for the periods selected in the estimation procedure, which resulted into 150 observations for the estimation period and 21 observations for the event window.

More specifically, the parameters of the three windows defining the event study

\begin{tabular}{|c|c|c|}
\hline Estimation window & Event Window & window \\
\hline $\begin{array}{l}31 \text { July } 2014 \text { until } 27 \\
\text { December } 2014\end{array}$ & $\begin{array}{l}28 \text { December } 2014 \text { until } 17 \text { January } \\
2015 \mathrm{~m} \text { with t0 on January } 7^{\text {th }}\end{array}$ & Days to rebound \\
\hline $\begin{array}{ll}-160 & -10\end{array}$ & +10 & \\
\hline
\end{tabular}
are stated in Figure 3.

Figure 3. Estimation, Event and post event window related to the study 
The estimation window will be used in order to calculate the mean return for CAC40 index for the period of 150 trading days as suggested by Corrado and Zivney (1992), from July 31, 2014 until December 27, 2014. In the event window, abnormal returns will be calculated using the mean adjusted model and tested for significance using a t-test, in order to test the efficiency of the French market in absorbing the effect of an unexpected terrorist attack. Finally, the post event window will be used to calculate the number of days CAC40 took after the attack in order to rebound back to its original value.

The event window $-10,+10$ will be divided into different sub-windows (Figure 4 ) in order to have a better understanding of the abnormal returns.

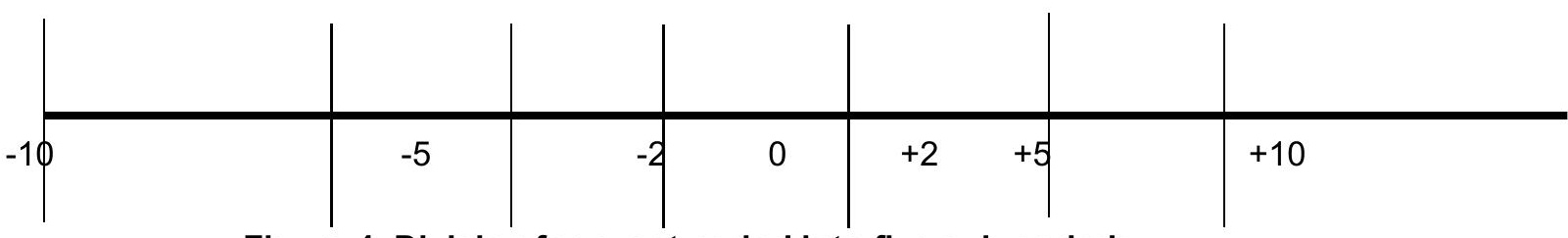

Figure 4. Division for event period into five sub-periods

Abnormal returns are calculated for the event window that goes from December 28, 2014 until January 17, 2015. The mean adjusted return model, which is a simple model that relies on the average return calculated in the estimation period, is used to calculate the conditional return. Binder (1998) added that in order to mitigate the bias caused while estimating the parameters (alpha and beta) in the market model, it seems better to use the mean adjusted return model than other complicated models. Accordingly, abnormal returns were calculated for the event window period for 21 trading days following the formula in Equation $5 . \bar{R}_{j}$ is the mean of CAC40 index daily return in the estimation period using Equation 9.

$$
\overline{\mathbf{R}}_{\mathrm{CAC40}}=\frac{1}{150} \sum_{-10}^{-160} \mathbf{R}_{\mathrm{CAC40,(-160,-10)}}
$$

Table 1 summarizes the abnormal returns calculated in the event window, using the mean adjusted return model, for 21 trading days including the 7th of January 2015 (the actual date of the French terrorist attack).

\section{Table 1}

Abnormal Returns for the Event Window

\begin{tabular}{lll}
\hline Day & Date & Abnormal Return \\
\hline 10 & $1 / 21 / 2015$ & -0.006696066 \\
9 & $1 / 20 / 2015$ & -0.003936116 \\
8 & $1 / 19 / 2015$ & -0.00518196 \\
7 & $1 / 16 / 2015$ & -0.001678031 \\
6 & $1 / 15 / 2015$ & -0.005793606 \\
5 & $1 / 14 / 2015$ & -0.010322071 \\
4 & $1 / 13 / 2015$ & 0.006677318 \\
3 & $1 / 12 / 2015$ & -0.006488471 \\
2 & $1 / 9 / 2015$ & -0.005242538 \\
\hline
\end{tabular}




\begin{tabular}{lll}
\hline 1 & $1 / 8 / 2015$ & 0.008186825 \\
$\mathbf{0}$ & $\mathbf{1 / 7 / 2 0 1 5}$ & $\mathbf{0 . 0 1 5 4 6 1 2 7 6}$ \\
-1 & $1 / 6 / 2015$ & -0.003260148 \\
-2 & $1 / 5 / 2015$ & 0.002790421 \\
-3 & $1 / 2 / 2015$ & 0.014474877 \\
-4 & $12 / 31 / 2014$ & 0.001922093 \\
-5 & $12 / 30 / 2014$ & -0.002937052 \\
-6 & $12 / 29 / 2014$ & 0.007180164 \\
-7 & $12 / 24 / 2014$ & -0.002389007 \\
-8 & $12 / 23 / 2014$ & 0.001766173 \\
-9 & $12 / 22 / 2014$ & -0.006298912 \\
-10 & $12 / 19 / 2014$ & -0.001469091 \\
\hline
\end{tabular}

According to Table 1, the abnormal return on January 7, 2015 which is the event day, is the lowest among all other days $(-0.0154)$. This lowest value of abnormal return directly turned out to be the second highest positive value of abnormal return directly on the day after the terrorist attack. In 2 days, abnormal returns turned again to be negative for the whole period after the terrorist attack, except for day 4. For further investigation, the event window will be divided into different periods and abnormal returns will be tested for significance in each period.

\section{Step 5: Testing Procedure}

The abnormal returns are tested using a 95\% confidence level in the different event window sub-periods. The test used in this study is a parametric one sample t-test as suggested by Brown and Warner (1980), Campbell et al (1997) and Fagerland (2012), where all of these researchers gave more statistical power for parametric tests and suggested their usage instead of non-parametric tests. Using STATA software, a one sample $t$ test (or known as mean comparison test) is used to test the significance of the abnormal returns creating the two hypotheses:

$\mathrm{H}_{0}$ : mean of abnormal returns $=0$

$\mathrm{H}_{1}$ : mean of abnormal returns $\neq 0$

\section{Step 6: Empirical Results}

In order to better understand the results, abnormal returns are calculated for each of the sub-periods shown in Figure 4. The abnormal returns in the event window are divided into two sub-periods: before and after the event day. Table 2 shows the results for the reaction of the market to the "Charlie Hebdo" terrorist attack.

\section{Table 2}

\section{Abnormal returns for the event window}

\begin{tabular}{lllll}
\hline Day Range & Mean & Standard Deviation & T-values & Significance \\
\hline Event Window & & & & \\
{$[-10,+10]$} & -0.0016265 & 0.0068457 & -1.0888 & Insignificant \\
{$[-5,+5]$} & -0.0008782 & 0.0087096 & -0.3344 & Insignificant \\
{$[-2 .+2]$} & -0.0025973 & 0.0089197 & -0.6511 & Insignificant \\
Before the Event & & & \\
\hline
\end{tabular}




\begin{tabular}{lllll}
\hline Day Range & Mean & Standard Deviation & T-values & Significance \\
\hline$[-10,0]$ & -0.0003347 & 0.0076177 & -0.1457 & Insignificant \\
{$[-5.0]$} & -0.0006913 & 0.004647 & -0.3644 & Insignificant \\
{$[-5,-2]$} & 0.0040626 & 0.0073849 & 1.1002 & Insignificant \\
{$[-2,0]$} & -0.0005310 & 0.009297 & 0.9893 & Insignificant \\
After the Event & & & & Significant at $5 \%$ \\
{$[0,+10]$} & -0.0041711 & 0.0067715 & -2.0454 & Insignificant \\
{$[0,+2]$} & -0.0041723 & 0.0118603 & -0.6093 & Insignificant \\
{$[+2,+5]$} & -0.0038439 & 0.0073397 & -1.0474 & Significant at $1 \%$ \\
{$[+5,+10]$} & -0.0056013 & 0.0028935 & -4.7418 & \\
\hline
\end{tabular}

The first notice is that all periods except $[-5,-2]$ showed negative mean returns for the event period with the second lowest one being on the closest range day to the event day $[0,+2]$. Obviously, this same period had the highest standard deviation resulting in high fluctuations in the index price on this day range. Abnormal returns in all event windows $[-10,+10] ;[-5,+5]$ and $[-2,+2]$ were negative and insignificant.

The mean abnormal returns for the periods before the attack $[-10,-0],[-10,-5]$ and $[-2,0]$ were negative and insignificant. As for the period $[-5,-2]$, the mean abnormal returns were positive for the first time but insignificant, suggesting no significant abnormal returns before the attack. Similar results are obtained in the event window where the mean abnormal returns were negative and insignificant. Surprisingly, the results show that the mean abnormal returns were insignificant for all the periods tested except for the two periods related to the day ranges $[0,+10]$ and $[+5,+10]$ which should have a deeper explanation, to be discussed later on.

Consequently, the most important result is the one related to the $[0,+2]$ day range, which indicates that the abnormal returns were insignificant, directly after the terrorist attack, accepting the null hypothesis, and concluding that the market is semi strong efficient. On the $[+2,+5]$ day range, abnormal returns were also insignificant, but the standard deviation was very high. Finally, the abnormal returns were significant only in the two periods $[0,+10]$ and $[+5,+10]$.

As for the cumulative abnormal returns, Table 3 shows a negative Cumulative Abnormal Return (CAR) on the event day (Day 0). On Day 1, the CAR flips its sign from a negative value to a positive one which means that the CAC40 index took only 1 day to rebound to its original level before the "Charlie Hebdo" attack. Surprisingly, after 2 days, CAR was again negative for 8 consecutive days which asserts the existence of another significant event that happened as a consequence of the "Charlie Hebdo" attack and caused this unexpected fluctuation in the index price.

\section{Table 3}

Cumulative Abnormal Returns for 10 days after the terrorist attack

\begin{tabular}{lll}
\hline Day & Date & Abnormal Return \\
\hline 10 & $1 / 21 / 2015$ & -0.034156474 \\
9 & $1 / 20 / 2015$ & -0.027460408 \\
8 & $1 / 19 / 2015$ & -0.023524293 \\
7 & $1 / 16 / 2015$ & -0.018342332 \\
\hline
\end{tabular}




\begin{tabular}{lll}
\hline 6 & $1 / 15 / 2015$ & -0.016664302 \\
5 & $1 / 14 / 2015$ & -0.010870696 \\
4 & $1 / 13 / 2015$ & -0.000548625 \\
3 & $1 / 12 / 2015$ & -0.007225943 \\
2 & $1 / 9 / 2015$ & -0.000737472 \\
1 & $1 / 8 / 2015$ & 0.004505066 \\
0 & $1 / 7 / 2015$ & -0.003681759 \\
\hline
\end{tabular}

To understand more the reaction of CAC40 index to the terrorist attack, Figure 5 displays a graphical presentation of the abnormal return on CAC40 index over time. On the event day $(\mathrm{t}=0)$, there has been a drop in the returns, which was quickly absorbed in less than one day. Strong mean reversion took the returns back to the pre attack level which is a sign of market resilience. CARs decreased again after 2 days before increasing back to the original value in 2 days. The graph shows that after 4 days from the terrorist attack, CARs had a remarkable decrease, leading to the negative abnormal returns calculated in table 2, confirming the presence of another shock or event causing the market to decline sharply.

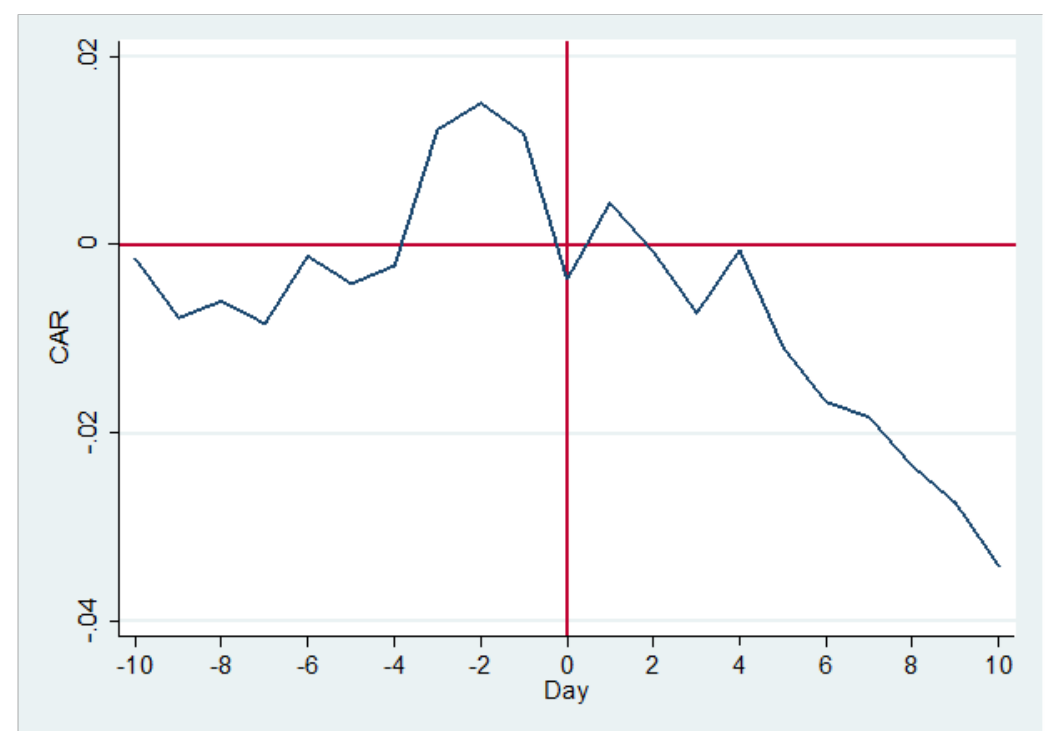

Figure 5. The CARs of the CAC40 index at the "Charlie Hebdo" terrorist attack

\section{Step 7: Interpretation and Conclusion}

During the 20 days event period, the abnormal returns were insignificant throughout the entire period, negative with the exception of only one period $[-5,-2]$ where abnormal returns were positive. The negative mean abnormal return in the $[-10,+10],[-5$, $+5]$, and [-2, +2] periods could be due to the negative return after the terrorist attack, although it was not significant. However, while taking into consideration the period before the attack and dividing it into different parts, $[-10,-5],[-5,-2]$ and $[-2,0]$, the abnormal returns were negative for two periods and positive in one period but always insignificant which means that the CAC40 index was nearly stable for this week with no significant increase or decrease in its price. 
The insignificance of the abnormal returns in the [0, +2] period suggests that the CAC40 index was very fast in its reaction to the attack, and its price was directly amended in order to take the sudden attack into consideration. The latter means that the French market was very efficient in absorbing the consequences of the attack on this small day range $[0,+2]$. On the $[+2,+5]$ period, abnormal returns were also insignificant but with high standard deviation, which means that the CAC40 index price has widen from the mean after the terrorist attack.

Finally, Table 2 shows that the mean abnormal return during $[0,+10]$ was negative and significant at $5 \%$ percent $(\operatorname{Pr}(T<t)=0.0340)$. Consequently, when this period is separated into smaller time intervals $[0,+2],[+2,+5]$ and $[+5,+10]$, results show that the first two periods had insignificant returns. Conversely, the last period $[+5,+10]$ had a significant negative return at $1 \%(\operatorname{Pr}(\mathrm{T}<\mathrm{t})=0.002)$ which suggest that the significance of the abnormal returns in the $[0,+10]$ period had started after 5 days from the attack and it is not related to the $[0,+5]$ period. Furthermore, Table 3 shows that CAR returns were always negative. It improved after 2 days from the attack, before starting to decline after day 5 . The CAR in Day 10 is the lowest among all days. The last period $[+5,+10]$ that belongs to the event window $[-10,+10]$ had the highest negative significant abnormal return. This point must have a deep understanding because it suggests that another event or events might took place directly after the attack, which had a bigger influence on the index price than "Charlie Hebdo" terrorist attack.

A very important issue that should be better investigated, and that could explain this late significant reaction of the CAC40 index is the ongoing threat of ISIS directly after the "Charlie Hebdo" attack. This was publicly admitted by the French president Francois Hollande after the terrorist attack and which could have influenced the CAC40 index more than the attack itself.

\section{Conclusion}

An efficient market is where all investors are well informed about all relevant information, and stock prices quickly adjust to new information. Accordingly, no investor can beat the market by generating abnormal returns. In the semi-strong form efficiency, stock prices reflect all public information, so technical and fundamental analysis are useless. Although the Efficient Market Hypothesis is a simple theory in principle, it is yet debatable whether the market follows the rules of EMH. Anomalies in stock markets remain an unsolved area. Thus, the purpose of this paper was to investigate the Efficient Market Hypothesis (EMH) in the French market, by testing its semi-strong form. The semi strong form market efficiency was tested by analyzing the impact of the terrorist attack of "Charlie Hebdo" that took place on the 7th of January 2015, by using observations from July 31, 2014 until January 19, 2015.

An event study methodology had been adopted. Twenty days were taken as the event window and then divided into different sub-windows in order to estimate the effect of the attack. Using a student t-test to measure the significance of the calculated abnormal returns, results of the event study methodology showed that on the day of the attack, the market was semi strong efficient and completely absorbed the effect of the attack so that 
investors were unable to generate abnormal returns upon the attack. The major finding related to this part was the significance of the negative abnormal returns after 5 days from the attack. This late significant reaction of the CAC40 index can be explained by the ongoing threat of ISIS after the terrorist attack. After the attack took place, different politicians admitted how dangerous the situation has become. An unnamed French senior counter terrorism official argued to the AFP (Agence France-Presse) that he is expecting a European 9/11, admitting that terrorists are working on several simultaneous attacks in other European countries (Todd, 2016). Jean-Charles Brisard, chairman of the "Centre d'Analyse du Terrorisme" questioned the ability of French security services to prevent such terrorist attack and added that terrorist movements are preparing for the worst in 2016 (Todd, 2016).

This papers suffers from some limitations. This paper tested the semi-strong market efficiency by examining the impact that only one terrorist attack- "Charlie Hebdo" which took place on the 7th of January 2015- had on CAC40 index. Even though "Charlie Hebdo" attack had captured high attention in the last couple of years and it was considered as one of the most important terrorism related event in the recent history next to the September 11th attack on the American twin towers, and the bombings in Madrid (2004) and London (2005), other related influencing events which could have an impact on the world's economy should be studied. Rather than considering only one terrorist attack, different terrorist attacks could be studied to test whether the semi strong market efficiency holds or possible abnormal returns could be realized following terrorist attacks. It is also recommended to test price to earning ratio, book to market ratio, post announcement earning drift in order to test the semi-strong market efficiency.

\section{References}

Agarwalla, S., \& Pandey, A. (2010, March 16). Price impact of block trades and price behavior surrounding block trades in Indian Capital Market. Available at SSRN: http://dx.doi.org/10.2139/ssrn.1572997.

Alzahrani, A., Gregoriou, A., \& Hudson, R. (2012). Price impact of block trades in the Saudi Stock Market. Journal of International Financial Markets, Institutions \& Money, 23, 322-341.

Archana, S., Safeer, M., \& Kevin, S. (2014). A study on market anomalies in Indian stock market. International Journal of Business and Administration Research and Review, 1(3), 128-137.

Armitage, S. (1995). Event study methods and evidence on their performance. Journal of Economic Surveys, 9(1), 25-52.

Bachelier, L. (1900). Théorie de la spéculation. Annales Scientifiques de l'École Normale Supérieure, 3 (17), 21-86.

Garcia De Andoain, C, \& Bacon, F. (2009). The impact of stock spit announcements on stock price: A test of market efficiency. Proceedings of American Society of Business and Behavioral Sciences (ASBBS), 16 (1), 1-14.

Ball, R., \& Brown, P. (1968). A retrospective. American Accounting Association, 89(1), 1-44.

Barnato, K. (2015). Europe, Canada face rising terror threat. CNBC. Retrieved from http://www.cnbc.com/2015/05/25/europe-canada-australia-face-rising-terror-threatreport.html.

Barros, C., \& Gil-Alana, L. (2008). Stock market returns and terrorist violence: evidence from the Basque Country. Applied Economics Letters, 16 (15), 1575-1579. 
Bauman, W. (1964). Investment experience with less popular common stocks. Financial Analysts Journal, 20(2), 79-88.

Benos, A., \& Rockinger, M. (2000). Market response to earnings announcements and interim reports: an analysis of SBF120 companies. Annales D'économie et de statistique, 60, 151-175.

Binder, J. (1998). The event study methodology since 1969. Review of Quantitative Finance and Accounting, 11(2), 111-137.

Bowman, R. (2006). Understanding and conducting event studies. Journal of Business Finance and Accounting, 10(4), 561-584.

Brown, S., \& Warner, J. (1980). Measuring security price performance. Journal of Financial Economics, 8(3), 205-258.

Brown, S., \& Warner, J. (1985). Using daily stock returns; the case of event studies. Journal of Financial Economics, 14 (1), 3-31.

Bruck, T., \& Wickstrom, B.A. (2004). The economic consequences of terror: guest editors introduction. European Journal of Political Economy, 20(2), 293-300.

Cam, M.A. (2007). The impact of terrorist attacks on financial markets (master thesis). RMIT University, Melbourne, Australia.

Campbell, J., Lo, W., \& MacKinlay, G. (1997). The Econometrics of Financial Markets. New Jersey: Princeton University Press.

Chandra, R., Moriarity, S., \& Willinger, L. (1990). A reexamination of the power of alternative returngenerating models and effect of accounting for cross-sectional dependencies in event studies. Journal of Accounting Research, 28(2), 398-408.

Chen, A., \& Siems, T. (2004). The effects of terrorism on global capital markets. European Journal of Political Economy, 20(2), 349-366.

Chesney, M., Reshetar, G., \& Karaman, M. (2011). The impact of terrorism on financial markets: an empirical study. Journal of Banking and Finance, 35 (2), 253-267.

Colman, L. (2012). Testing equity market efficiency around terrorist attacks. Applied Economics, 44(31), 4087-4099.

Corrado, C., \& Zivney, T. (1992). The specification and power of the sign test in event study hypothesis tests using daily stock returns. Journal of Financial and Quantitative Analysis, 27(3), 265-478.

Dimson, E., \& Mussavian, M. (1998). A brief history of market efficiency. European financial management, 4(1), 91-19

Dolley, J. (1933). Characteristics and procedure of stock common stock split ups. Harvard Business Review, 11(3), 316-326.

Drakos, K. (2010). Terrorism activity, investor sentiment and stock returns. Review of Financial Economics, 19 (3), 128-135

Enders, W., \& Sandler, T. (2006). Terrorism and foreign direct investment in Spain and Greece. Kyklos International Review of Social Sciences, 49(3), 331-352.

Fagerland, M. (2012). T-tests, non parametric tests, and large studies- a paradox of statistical practice? BMC Medical Research Methodology, 12(1), 78-84

Fama, E. (1970). Random walks in stock market prices. Financial Analysts Journal, 51(1), 75-80.

Fama, E. (1991). Efficient capital markets: II. The Journal of Finance, 46(5), 1575-1617.

Fama, E., Lawrence, F., Michael, J. \& Richard, R. (1969). The Adjustment of Stock Prices to New Information. International Economic Review, 10(1), 1-21.

Hameed, A., Ashraf, H., \& Siddiqui, R. (2006). Stock market volatility and weak-form efficiency: evidence from an emerging country. The Pakistan Development Review, 45(4),1029-1040.

Hua, L. \& Ramesh, S. (2013). A study on stock split announcements and its impact on stock prices in Colombo stock exchange (CSE) of Sri Lanka. Global Journal of Management and Business Research Finance, 13(6), 25-34. 
Karolyi, G.A., \& Martell, R. (2006). Terrorism and the stock market. International Review of Applied Financial Issues and Economics, 2(2), 285-314.

Kollias, C., Papadamou, S., \& Arvanitis, V. (2013). Does terrorism affect the stockbond covariance? Evidence from European countries. Southern Economic Journal, 79 (4), 832-548.

Lardic, S., \& Mignon, V. (2003). Analyse intraquotidienne de l'impact de "news" sur le marché boursier francais. Economie appliquée (Paris), 56 (2), 205-237.

Lo, A., \& MacKinlay, A. C. (1988). Stock market prices do not follow random walks: evidence from a simple specification test. The review of Financial Studies, 1(1), 41-66.

Rehman, A., Luqman, M., \& Suleman M. U. (2011, September 16). Evaluation of semi strong form of efficiency: an empirical study on Karachi stock exchange with respect to natural disasters and terrorism effects. Available at SSRN: http://dx.doi.org/10.2139/ssrn.2326338.

Malkiel, B. (2003). The efficient market hypothesis and its critics. Journal of Economic Perspectives, $17(1), 59-82$.

Mallikarjunappa, T., \& Dsouza, J.J. (2013). A study of semi-strong form of market efficiency of Indian stock market. Amity Global Business Review, 8, 60-68.

Nikkinen, J., Omran, M., Sahlstrom, P, \& Aijo, J. (2008). Stock returns and volatility following the September 11 attacks: Evidence from 53 equity markets. International Review of Financial Analysis, 17 (1), 27-46.

Peterson, P. (1989). Event studies: a review of issues and methodology. Quarterly Journal of Business and Economics, 28(3), 36-66.

Ross, S. (1976). The arbitrage theory of capital asset pricing. Journal of Economic Theory, 13(3), 341-360.

Ryland, P (2009). Essential Investment: an A-Z guide (2nd ed.). New York: Bloomberg Press

Schwert, G.W. (2003). Anomalies and market efficiency. Handbook of the Economics and Finance, $1(\mathrm{~B}), 939-974$.

Suleman, M. (2012). Stock market reaction to terrorist attacks: Empirical evidence from a front line state. Australasian Accounting Business and Finance Journal, 6(1), 97-110.

Todd, T. (2016, January 12). French 2015 terror attacks a "dress rehearsal" for 2016, experts say. France 24. Retrieved from http://www.france24.com/en/20160111-france-november-13paris-attacks-terrorism-charlie-hebdo-intelligence-security. 